\title{
HISTÓRIA DA INSTITUCIONALIZAÇÃO DA EDUCAÇÃO INFANTIL: DOS ESPAÇOS DE ASSISTÊNCIA À OBRIGATORIEDADE DE ENSINO (1875-2013)
}

\begin{abstract}
Priscila Viviane de Souza Filipim ${ }^{1}$
Ednéia Regina Rossi ${ }^{2}$ Elaine Rodrigues ${ }^{3}$

\section{Resumo}

Neste artigo, a intenção é abordar a história da institucionalização da educação infantil no Brasil, tendo como fonte a legislação brasileira e pesquisas realizadas sobre o tema. As nomenclaturas existentes para as instituições deste nível encerram, em si, conceitos e finalidades distintos e estão atreladas aos contextos históricos de seus países de origem. Ao longo da idade moderna, criou-se um conceito de infância e o entendimento da importância de estímulos para o seu desenvolvimento. Essa mentalidade impulsiona iniciativas de criação de espaços exclusivos de formação e a compreensão do direito da criança à educação. Essa visão é contemplada no texto da Constituição Federal do Brasil de 1988 e no Estatuto da criança e do adolescente - Lei no 8.069/90. Assim, como direito, a Lei de Diretrizes e Bases da Educação Nacional (LDBEN, $n^{\circ}$ 9.394/96) insere a educação infantil no sistema de educação nacional, sendo a obrigatoriedade de parte deste nível instituída pela Lei 12.796 de 2013. Correlatas a essas mudanças, as Diretrizes Curriculares Nacionais para a Educação Infantil propagam a ideia educacional de indissociabilidade do cuidar, do educar e do brincar.
\end{abstract}

Palavras-chave: História da institucionalização da educação infantil. Legislação educacional. Obrigatoriedade da educação infantil.

\section{HISTORY OF CHILDHOOD EDUCATION INSTITUTIONALIZATION: FROM ASSISTANCE SPACES TO OBBLIGATORY SCHOOLING (1875-2013)}

\begin{abstract}
This article aims at approaching the history of childhood education institutionalization in Brazil, having as source Brazilian legislation and research done on the thematic. The existing nomenclatures for the institutions of this level end, in themselves, distinct concepts and purposes and are linked to the historical contexts of their country of origin. Throughout the modern age, a concept of childhood and the understanding of the importance of the stimulus for its development were created. This mentality boosts initiatives for creation of exclusive spaces for formation and comprehension of the child's right to education. This vision is contemplated in the text of The Federal Constitution of Brazil from 1988 and on the Child and Adolescents Statute - Law n ${ }^{\circ}$ 8069/90. Therefore, as a right, The National Education Bases and Guidelines Law (LDBEN, $\mathrm{n}^{\circ}$ 9394/96)
\end{abstract}


inserts childhood education in the national education system, being its obligatoriness instituted by Law 12.796 of 2013. Correlated to these changes, the National Curriculum Guidelines for Childhood Education propagate the educational idea of the inseparability of caring, educating and playing.

Keywords: History of childhood education institutionalization. Educational legislation. Childhood learning obligatoriness.

\section{INTRODUÇÃO}

Neste artigo, a intenção é analisar como a história da educação infantil se construiu progressivamente, no Brasil, como uma prática institucional-escolar. O recorte temporal será o ano de 1875, quando foi criado o primeiro jardim de infância na cidade do Rio de Janeiro, até 2013, quando foi aprovada a ampliação da obrigatoriedade de ensino no Brasil dos quatro aos 17 anos, abrangendo parte da educação infantil.

Trata-se de uma pesquisa de caráter documental e bibliográfica, tendo como fonte leis e decretos que tratam da organização da educação infantil no Brasil, assim como autores que debatem esta temática. A partir dos documentos, analisamos os conteúdos e organizamos as discussões em torno da unidade de análise definida como tema.

O desafio foi construir um quadro analítico das instituições que se ocuparam da educação infantil a partir de nomenclaturas e conceitos presentes na legislação brasileira. A abordagem desta temática remeteu ao fato de que a educação infantil não ocorreu em um único modelo institucional. Ao contrário, há uma multiplicidade de instituições que se ocuparam desse fazer, como, por exemplo, creches, escolas maternais e jardins de infância.

Estudiosos que se debruçam no debate desta temática não possuem uma interpretação hegemônica em relação aos objetivos e finalidades destas diferentes instituições. Algumas pesquisas propõem uma análise que divide as instituições entre assistenciais e educacionais. Não pretendemos fazer uma crítica a essas classificações, mas evidenciar a existência de interpretações diferentes e, ao fazê-lo, problematizar análises que priorizam uma racionalidade de enquadramentos dualistas, como racional/irracional, bom/ruim, rico/pobre, assistencial/educacional.

Transitaremos no sentido de pensar que os sujeitos que se dedicaram à educação das crianças pequenas se ocuparam do desafio de cuidá-las e de educá-las em contextos e historicidades distintos. Nossa interpretação encontra respaldo teórico nas análises de Chartier (1991) que, ao problematizar a percepção do real como algo extremamente objetivo, oferece suporte para pensar que a percepção do real é uma representação compartilhada por indivíduos de um mesmo grupo social. As práticas culturais e seus objetos não podem ser classificados de acordo com divisões sociais prévias "[...] identificadas a partir de diferenças de Estado e de fortuna". (CHARTIER, 1991, p. 177). 
Entendemos que a análise das estruturas internas e do funcionamento das diferentes instituições de educação infantil poderiam revelar suas reais práticas. Desta forma, agregaríamos elementos desta prática ordinária na análise de seus objetivos e finalidades institucionais.

Iniciamos nossas considerações recuperando a memória de espaços, como orfanatos e asilos, que possuíam caráter assistencial, havendo uma parceria entre o Estado, Irmandades religiosas e senhoras da sociedade. Contudo, nossa preocupação está em sinalizar a criação de entidades com prática institucional escolar.

É importante considerar que creches, escolas maternais e jardins de infância são nomenclaturas criadas na Europa, no século XIX, e que inspiraram o Brasil na criação de seus espaços. A diversidade de nomenclaturas institucionais esconde conceitos e soluções dadas para a educação das crianças pequenas. Estes conceitos foram incorporados e ressignificados no Brasil no processo de institucionalização da educação infantil.

A legislação brasileira, em diferentes momentos históricos, faz referência a jardins de infância, pré-primário, escolas maternais, creches e pré-escolar. A partir de 2013, consolida-se, no sistema de educação brasileiro, um modelo de atendimento às crianças dos zero aos cinco anos de idade, sendo instituída a obrigatoriedade a partir dos quatro anos. Propaga-se, também, uma visão integrada do desenvolvimento da criança, com base em concepções que respeitem a indissociabilidade do cuidar, do educar e do brincar.

\section{EDUCAÇÃO INFANTIL NO BRASIL}

As instituições de educação infantil propagam-se, internacionalmente, a partir da década de 1870. (KUHLMANN JUNIOR, 2000a). Foi também nesta década que a elite intelectual brasileira manteve-se vigilante com os avanços educacionais que circulavam pela Europa e Estados Unidos. (SOUZA, 2013). Observa-se então, que o período do final do Império mostrava-se como profícuo ao debate e à mudança no campo educacional. É importante destacar que as primeiras instituições de educação infantil no Brasil datam desta época.

No entanto, convém esclarecer que antes deste período, práticas se instituíram, ao longo do tempo, evidenciando um progressivo cuidado com as crianças. A literatura aborda que, no século XVII, no Brasil, era comum o abandono das crianças em portas de casas, em igrejas e nas ruas. Esta prática torna-se um problema, levando a Corte Imperial a adotar, para estes casos, o mesmo atendimento adotado em Portugal e na Europa.

Esse atendimento ficava a cargo das Santas Casas de Misericórdia, que exerciam papel de caridade em parceria com o Corte. As municipalidades, naquela época, repassaram oficialmente este dever a Irmandade de Nossa Senhora. É neste contexto que se cria, como proteção oficial, a chamada roda dos expostos. A roda dos expostos teve origem 
na Itália, durante a Idade Média, a partir do trabalho de uma Irmandade de Caridade preocupada com o grande número de bebês abandonados e encontrados mortos.

No Brasil do século XVIII, a roda dos expostos pode ser compreendida como um sistema de proteção formal no qual a Corte firma convênio com as Irmandades. Foram as primeiras iniciativas de atendimento à criança abandonada. A princípio, foram três: Salvador (1726), Rio de Janeiro (1738), Recife (1789), e, mais tarde, em São Paulo (1825). Outras rodas menores foram surgindo em outras cidades após esse período. O intuito desta ação era esconder a vergonha de mães solteiras, bem como resguardar os filhos de uniões ilegítimas que eram abandonados. Os indivíduos deixavam a criança na "roda" e se retiravam do local, preservando sua identidade. Segundo Aquino:

\begin{abstract}
A roda dos expostos, como assistência caritativa, era, pois, missionária. A primeira preocupação do sistema para com a criança nela deixada era de providenciar o batismo, salvando a alma da criança, a menos que trouxesse consigo um bilhete - o que era muito comum - que informava à rodeira de que o bebê já estava batizado. No caso de dúvida dos responsáveis pela instituição, a criança era novamente batizada. (2001, p. 31).
\end{abstract}

A Roda dos expostos, também conhecida como Roda dos Enjeitados, por muitos anos, foi a única instituição de assistência à criança desamparada no Brasil; o sistema foi extinto somente no século XX.

É importante observar que, ao se abordar o tema da educação das crianças pequenas, a discussão se mistura com a história dos direitos da infância, daquilo que socialmente foi sendo construído como compreensão da própria infância e dos direitos que ela possui. Trata-se de um processo de mudança de hábitos e práticas no sentido da defesa da pessoa humana. Estudos têm assinalado que, quando o tema é a criação de espaços específicos cujo objetivo é a educação, tal iniciativa, no Brasil, desenvolveu-se no final do século XIX, quando o governo, de maneira oficial, pronunciou-se em relação aos alunos que não possuíam a idade mínima de sete anos para adentrar nas escolas primárias. Segundo Drouet (1990), a primeira referência oficial à educação das crianças pequenas em nosso país encontra-se no projeto da Reforma Leôncio de Carvalho, em 1879, ainda no Período Imperial.

Esse projeto reformou a instrução pública primária e secundária no Município da Corte e, naquela época, este local possuía o poder simbólico de ser a vitrine da nação. Em seu artigo $2^{\circ}$, estabelece a obrigatoriedade de frequência às escolas primárias a partir dos sete anos e prevê, em seu artigo $5^{\circ}$, que: "Serão fundados em cada distrito do município da Corte, e confiados à direção de Professoras, jardins da infância para a primeira educação dos meninos e meninas de 3 a 7 anos de idade". (BRASIL, 1879, realizou-se atualização ortográfica).

Embora no Decreto de 1879 a educação das crianças pequenas figure como preocupação da Corte brasileira, e fazendo parte da política educacional do Município do Rio de Janeiro, é importante destacar que o jardim de infância já existia no Brasil enquanto iniciativa particular. Em 1875, foi fundado, no Rio de Janeiro, o primeiro jardim de 
infância privado do país, idealizado pelo médico e também educador da Corte, Joaquim José Menezes Vieira. Localizado num dos melhores bairros da cidade, com excelente espaço físico, destinou-se ao atendimento da elite, sendo somente para crianças do sexo masculino.

Em 1875 instala, juntamente com sua esposa, D. Carlota de Menezes Vieira, um jardim de crianças no Colégio Menezes Vieira, situado na Rua dos Inválidos, $\mathrm{n}^{\mathbf{0}}$. 26, em um dos melhores bairros da cidade do Rio de Janeiro, com ótimas instalações - um pavilhão hexagonal, especialmente construído no centro do jardim, com ar e luz por quatro janelas. (BASTOS, 2001, p. 32).

O jardim de infância do Colégio Menezes Vieira utilizava a metodologia propagada por Johann H. Pestalozzi (1746-1827) e as atividades sugeridas por Friedrich Froebel (1782-1852) e Marie Pape-Carpantier ${ }^{5}$, tendo o método intuitivo como desenvolvimento da percepção direta e experimental das crianças. Seu objetivo era atender crianças de três a sete anos de idade, com atividades relacionadas à ginástica, à pintura, ao desenho, aos exercícios de linguagem e de cálculo, escrita, leitura, história, geografia e religião.

O conceito de jardim de infância foi utilizado pela primeira vez por Froebel, quando, em 1840, cria a primeira instituição em Oberweissbach, no sudeste da Alemanha. Sua finalidade era educar as crianças a partir dos quatro anos de idade. Froebel era discípulo de Pestalozzi e fez avançar as ideias de seu mestre no campo da educação préescolar. Influenciado por um ideal de liberdade, propôs a criação dos kindergardens, que significa kind = criança e garden = jardim, ou seja, os jardins de infância, onde as crianças estariam livres para aprender sobre si mesmas e sobre o mundo. Ao criar o Jardim de infância, pensava em abolir os asilos de criança do seu tempo.

A dedicação ao ato de ensinar e a afetividade com as crianças eram requisitos fundamentais para as jardineiras, nome dado às professoras destes espaços. Elas tinham a responsabilidade de adubar o solo, possibilitando às plantas uma florada saudável e viçosa, dando mais vida, entonação, cor, alegria e perfume aos jardins que nos remetem à sala de aula.

Um jardim é um lugar onde as plantas não crescem em estado totalmente silvestre, totalmente selvagem, é um lugar onde elas recebem os cuidados do jardineiro ou da jardineira. Mas, o jardineiro sabe que embora ele tenha por tarefa cuidar para que a planta tenha todo o necessário para seu crescimento e desenvolvimento, em última instância, é o processo natural da planta que deverá determinar quais cuidados a ela deverão ser dispensados. (ARCE, 2002, p. 1112).

Os jardins de infância seriam espaços idealizados para que houvesse proteção e carinho, para que as crianças pudessem desenvolver-se, tornando-se um sujeito bom. A preocupação com a organização pedagógica e com o desenvolvimento do conhecimento dar-se-ia pela exploração dos objetos e pela incorporação das experiências sensoriais que aconteceriam por meio das mãos, do corpo e do sentimento. (RIZZO, 1983). 
No caso brasileiro, o jardim de infância foi mencionado em lei do Município da Corte, em 1879, conforme mencionado anteriormente. Conforme o decreto, este estabelecimento atenderia crianças dos três aos sete anos de idade. E em relação às crianças menores de três anos? Haveria alguma instituição que se responsabilizasse por sua educação?

A essa pergunta responderíamos que não. Nos anos 70, do século XIX, não há notícias de instituições educativas para crianças abaixo de três anos. Apenas em 1899, foi criada a primeira creche de que se tem notícia na história brasileira, para atender os filhos de trabalhadores de uma fábrica - a creche da Companhia de Fiação e Tecidos Corcovado, no Rio de Janeiro. O termo creche origina-se do francês creche que equivale à manjedoura, presépio, sendo esta designação usada para referir-se ao atendimento de guarda e educação, fora da família, das crianças pequenas. Para Kuhlmann Junior (2000b, p. 471), essas instituições serviriam às "[...] mães pobres, que necessitassem trabalhar, e poderiam superar o obstáculo de não ter a quem confiar seus filhos cuja tenra idade não lhes permitia mandá-los para a escola".

$\mathrm{Na}$ França, a primeira creche foi criada em 1844, por Jean-Baptiste Firmin Marbeau, para atender crianças de zero a três anos. Segundo Zambon (2006), a creche francesa deveria fornecer à criança condições de um bom desenvolvimento; para muitas crianças, seria um lugar melhor do que a casa. Esta instituição valorizava os brinquedos e as brincadeiras, trazendo maior consciência do papel do jogo e do brinquedo na formação e desenvolvimento da criança. As creches atendiam crianças de mães trabalhadoras. Em 1846, existiam, na França, aproximadamente, 14 creches.

A criação das creches na França veio ao encontro das demandas de famílias menos favorecidas que passaram a vislumbrar uma alternativa para deixar seus filhos. A preocupação, nessa época, era com quem deixar as crianças para que recebessem cuidados e não ficassem sozinhas ou perambulando pelas ruas. $\mathrm{O}$ foco era protegê-los dos perigos que o mundo lhes impunha e este pensamento influenciou a implantação das primeiras instituições infantis em que o objetivo era zelar e cuidar das crianças.

O modelo institucional francês atendia a uma demanda bastante pragmática da sociedade que se industrializava e a mudanças que ocorriam na estrutura familiar, em que se observa uma redução do número de membros nas famílias e a constituição da família nuclear, feita, tradicionalmente, por pai e mãe, ou apenas um deles, e os filhos. Quando pai e mãe saem para o trabalho, cria-se o problema de onde deixar os filhos. É importante lembrar que, em outras sociedades, com estrutura familiar diferente, e com um trabalho em que seja possível conciliar a criação dos filhos, esta problemática não se coloca nas proporções em que ocorre com o advento da vida urbana.

No Brasil, na origem dos debates acerca das creches, havia a recomendação, em Congressos sobre a infância, para que elas fossem criadas junto às indústrias. Esta medida era debatida no contexto das necessidades de regulamentação das relações de trabalho, principalmente da mulher. Muitas creches foram criadas, nas primeiras décadas do século XX, vinculadas às indústrias. (KISHIMOTO, 1988). 
Kuhlmann Junior faz uma diferenciação entre os primeiros jardins de infância brasileiros e as creches. Para ele:

O jardim de infância, criado por Froebel, seria a instituição educativa por excelência, enquanto a creche e as escolas maternais - ou qualquer outro nome dado a instituições com características semelhantes às salles dástle francesas seriam assistenciais e não educariam. (KUHLMANN JUNIOR, 1998, p. 73).

$\mathrm{Na}$ interpretação de Kuhlmann Junior (1998), as diferentes nomenclaturas institucionais distinguiriam, também, suas finalidades. As creches e as escolas maternais, que corresponderiam às finalidades das "Salas de Asilo" francesas, teriam um fim assistencialista, e os jardins de infância teriam um fim educativo.

Neste ponto, as chamadas "Salas de Asilo" merecem uma elucidação. Na literatura que trata da educação de países, como a Inglaterra, a França e Portugal, encontra-se menção às chamadas "Salas de Asilo". Na França, a primeira teria se instalado em 1800, em Paris, chamada "Salle de Hospitallé", atendendo bebês de quinze dias a três anos de idade, filhos de mães operárias. Contudo, este empreendimento durou pouco por falta de recursos. Mais tarde, em 1826, foi instalada a primeira "Sala de Asilo" que tinha como modelo a iniciativa inglesa, qual seja, o princípio de uma iniciativa privada que aliava o trabalho de religiosas e senhoras da sociedade. Estes espaços destinavam-se ao atendimento de crianças desfavorecidas, sendo, posteriormente, criados pela iniciativa do Estado. As "Salas de Asilo" antecederam a criação das "Escolas maternais" na França. Alguns autores entendem que essas já defendiam uma proposta educacional, representado por Jean-Marie Denis Cochin em seu "Manual de asilos" publicado em 1833. (GARNIER, 2014; ZAMBON, 2006).

Identificamos uma divergência de interpretação em relação às finalidades da "Sala de Asilo". Alguns autores a identificam como instituição com proposta educacional, e outros, como espaço sem fins educacionais, sendo meramente assistencial. Estas mesmas interpretações dicotômicas podem ser observadas quando o assunto são as creches e as escolas maternais no Brasil.

Convém esclarecermos que, no contexto de criação das creches no Brasil, ou seja, em final do século XIX, não era um hábito o envio de crianças pequenas a uma instituição educativa. Em nossa cultura predominantemente agrária, as crianças pequenas eram educadas pelas famílias. Embora circulasse um debate internacional da importância de se iniciar a formação desde a mais tenra idade, fomentada por pensadores como Comenius (1592-1670), Locke (1632-1704) e Rousseau (1712-1778), a consolidação desta prática ainda estava em construção. No transcorrer dos séculos XVIII e XIX, propostas educacionais foram criadas, como exemplo, as dos pedagogos Pestalozzi (1746-1827) e Froebel (1782-1852), que inauguram, também, espaços institucionais inovadores e alinhados com a nova mentalidade moderna em formação. No caso brasileiro, no final do século XIX e nas primeiras décadas do século XX, a meta do poder público era garantir a frequência obrigatória das crianças no ensino primário. (ROSSI, 2004). 
Kuhlmann Junior (2001) registra que, em 1921, havia 15 creches no Brasil e, no ano de 1924, havia registro de 47 creches distribuídas em várias capitais brasileiras. No entanto, será a partir da década de 1960 que as intenções e as defesas da educação infantil começam a ganhar corpo na lei. Vale destacar que a Lei de Diretrizes e Bases da Educação Nacional (LDBEN) n ${ }^{\circ}$ 4.024/61 estabelecia que:

Art. 23 - A educação pré-primária destina-se aos menores até sete anos, e será ministrada em escolas maternais ou jardins de infância.

Art. 24. As empresas que tenham a seu serviço mães de menores de sete anos serão estimuladas a organizar e manter, por iniciativa própria ou em cooperação com os poderes públicos, instituições de educação pré-primária. (BRASIL, 1961).

Observa-se que a LDBEN de 1961 faz menção às escolas maternais e jardins de infância, como pertencentes à educação pré-primária. É importante destacar que a expressão "École maternalle", Escola Maternal, é oficialmente utilizada na França em 1848. Estas seriam gratuitas e atenderiam crianças de dois a seis anos. A "Escola maternal" está presente no Decreto de Reforma de Jules Ferry (1881) - Ministro da instrução pública, responsável pela criação do sistema francês de ensino público, que fixa faixa etária e regras para o funcionamento das Escolas Maternais, sendo destinada às crianças pobres, uma particularidade das instituições de educação infantil na época, uma vez que a prática social comum era que as famílias cuidassem de suas crianças pequenas. (GARNIER, 2014; ZAMBON, 2006).

Para Garnier (2014), a escola maternal seria uma continuidade das "salas de asilo". A alteração de denominação teria ocorrido pelos Republicanos, em 1881, que tinham a intenção de criar outra instituição que os representasse, distanciando-os da antiga Monarquia.

No caso brasileiro, segundo Kishimoto (1988), haveria duas vertentes de interpretação quanto às escolas maternais e jardins de infância. Uma delas partiria do entendimento de que a escola maternal se destinou ao atendimento de crianças de dois a quatro anos, enquanto o jardim de infância atenderia crianças a partir dos quatro anos de idade. Outra vertente interpreta a utilização de nomenclaturas diferentes justificadas pelos públicos a que eram destinadas, a escola maternal atenderia as crianças pobres, e o jardim de infância, as crianças de elite.

Vale lembrar que as escolas maternais no Brasil foram inspiradas pelas escolas maternais da França, a primeira de que se tem notícia foi em 1902, por iniciativa particular de Anália Franco. Segundo Kishimoto (1988), no transcorrer dos anos 20, os governos estaduais em parceria com religiosos, industriais e damas da sociedade criaram muitos destes estabelecimentos em indústrias e vilas operárias. Ao governo caberiam as despesas com professores, funcionários e materiais pedagógicos. As despesas com espaço físico e alimentação aos parceiros.

Vale destacar que, o contexto da LDBEN de 1961 é diferente dessas primeiras iniciativas. A lei definiu a educação pré-primária como aquela que acontece em escolas 
maternais e jardins de infância, no entanto não fica claro a partir de que idade este atendimento ocorreria. Oliveira (2002 p. 108) destaca o papel do governo militar na alteração da educação da criança pequena. Para ele:

\begin{abstract}
Novas mudanças na Consolidação das Leis de Trabalho, ocorridas em 1967, trataram o atendimento aos filhos das trabalhadoras apenas como questão de organização de berçários pelas empresas, abrindo espaço para que outras entidades, afora a própria empresa empregadora da mãe, realizassem aquela tarefa por meio de convênios. O poder público, contudo, não cumpriu o papel de fiscal da oferta de berçários pelas empresas. Assim, poucas creches e berçários foram nelas organizados.
\end{abstract}

É possível perceber a obrigatoriedade de organização de creches e berçários em empresas para o atendimento de filhos das trabalhadoras, no entanto vinculada as Leis de Trabalho. Esta relação nos remete ao fato de que a criação destes espaços esteve atrelada, neste momento, aos direitos das mulheres.

Mais tarde, com a revogação da LDBEN nº 4.024/61 pela Lei no 5.692 de onze de agosto de 1971, é possível perceber que a política para Educação Pré-Escolar permanece acanhada, sem muita especificidade em relação a educação pré-escolar. Ela faz referência a este nível em seu artigo $19, \S 2^{\circ}$, estabelecendo que “[...] os sistemas de ensino velarão para que as crianças de idade inferior a sete anos recebam conveniente educação em escolas maternais, jardins de infância e instituições equivalentes". Recomenda ainda, no artigo 61, que os sistemas estimulem "[...] as empresas que tenham em seus serviços mães de menores de sete anos a organizar e manter a educação que preceda o ensino de $1^{\circ}$ grau". (BRASIL, 1971).

Mesmo prevista em Lei, o ensino para crianças pequenas não atingiu o esperado na prática, já que não fazia parte do texto a obrigatoriedade do atendimento por parte do Estado. Segundo Sousa (1996, p. 41), “[...] as leis foram elaboradas de forma muito genérica, não contribuindo para disciplinar e responsabilizar os organismos públicos". Elas ficaram, na realidade, restritas a algumas escolas nos grandes centros urbanos do país.

Com esse cenário, convencionou-se que a educação pré-escolar era aquela oferecida a qualquer criança com idade inferior a sete anos, pois somente a partir dessa idade a educação era obrigatória e oferecida nas escolas. Antes dos sete anos, a educação seria direito e dever da família e, como tal, não obrigatória. Diante desse contexto, mulheres, sobretudo mães trabalhadoras, participaram intensamente dos movimentos que reivindicavam a criação de creches no Brasil. A partir de 1975, com a decretação, pela Organização das Nações Unidas (ONU), do Ano Internacional da Mulher, a luta intensifica-se, pois surgem, também, no país, núcleos de organizações feministas cujos participantes faziam parte, sobretudo, dos extratos médios da população.

É importante destacar que, em leis estaduais, instância a quem era delegada a responsabilidade pela educação pré-escolar, na década de 1970, encontramos uma classificação dos estabelecimentos deste nível de ensino, em que é feita menção à creche, à escola maternal e ao jardim de infância. Observemos a Deliberação nº 020/78 - Indicação 
n 001/78, do Conselho Estadual de Educação do Estado do Paraná (CEE) - Capítulo III, que fixa normas para a Educação Pré-Escolar:

\begin{abstract}
Art. $4^{\circ}$ - A Educação Pré-Escolar será desenvolvida em estabelecimentos denominados: a) creche: para crianças de zero até dois anos de idade completos; b) Escola Maternal: para crianças de 2 até 4 anos completos; c) Jardim de Infância: para crianças de 4 até 6 anos completos. $§ 1^{\circ}$ Liberdade de escolha do nome. É de livre escolha a denominação principal do estabelecimento, mencionando-se nela, porém, obrigatoriamente, a expressão 'Ensino PréEscolar', acompanhada da modalidade respectiva. § $2^{\circ}$ Integração no $1^{\circ}$ grau. $\mathrm{O}$ jardim de Infância poderá funcionar integrado à escola de Ensino de $1^{\circ}$ Grau ou isoladamente. (PARANÁ, 1978, p. 15).
\end{abstract}

Observa-se, neste texto da lei do Estado do Paraná, a existência de três nomenclaturas para os estabelecimentos de nível pré-escolar, sendo as creches destinadas ao atendimento de crianças de zero a dois anos, as escolas maternais para atendimento de crianças de dois a quatro anos, e o Jardim de Infância para crianças de quatro a seis anos. Verifica-se, ainda, que o jardim de infância poderia funcionar integrado ao ensino de primeiro grau.

Na década de 1980, com a promulgação da Constituição Federal de 1988, a educação infantil adquiriu maior destaque no cenário nacional, sendo compreendida como direito da criança e não mais atrelada ao direito da mulher e da mãe que trabalha. Nessa perspectiva, a Constituição, juntamente com o Estatuto da Criança e do Adolescente (ECA) - Lei $n^{\circ}$ 8.069/90, contribuíram para que a Educação Infantil fosse considerada, pela primeira vez, como etapa da Educação Básica, no texto da Lei de Diretrizes e Bases da Educação Nacional (LDBEN) n 9.394/96, que determina em seu título V, cap. II, seção II, Art. 29:

\footnotetext{
A educação infantil é considerada a primeira etapa da educação básica, tendo como finalidade o desenvolvimento integral da criança, até os seis ${ }^{6}$ anos de idade, nos aspectos físico, psicológico, intelectual e social, complementando a ação da família e da comunidade. (BRASIL, 1996).
}

Embora incorporada ao sistema de ensino, a educação infantil ainda não era obrigatória no texto da LDBEN de 1996, ou seja, não havia a exigência do atendimento da demanda de vagas existentes pelo poder público. O texto se restringe a explicitar a finalidade da Educação Infantil que convergiria com as intencionalidades da Educação Básica, de modo a garantir os alicerces para o crescimento saudável das crianças e seu progresso nas etapas posteriores.

Contudo, o texto da LDBEN ( $n^{\circ}$ 9.394/96) passou por alterações no decorrer dos anos e, dentre as alterações, a implantação da Lei no 12.796 de 2013. Damos destaque à alteração do art. $4^{\circ}$ da LDBEN, no qual a educação obrigatória e gratuita é estendida dos quatro (4) aos dezessete (17) anos de idade. Antes desta alteração, a LDBEN previa escolarização obrigatória apenas para o Ensino Fundamental, ou seja, dos seis (6) aos quatorze (14) anos de idade. Dessa forma, na nova redação, parte da Educação Infantil passou a ser obrigatória, implicando sanções aos responsáveis (família e Estado) que não 
respeitarem as novas regras. Assim institui a Lei $\mathrm{n}^{\circ} 12.796$ de 2013, no inciso I do artigo $4^{\mathrm{o}}:$

I - educação básica obrigatória e gratuita dos 4 (quatro) aos 17 (dezessete) anos de idade, organizada da seguinte forma:

a) pré-escola

b) ensino fundamental;

c) ensino médio. (BRASIL, 2013).

A mesma Lei institui em seu Artigo 30:

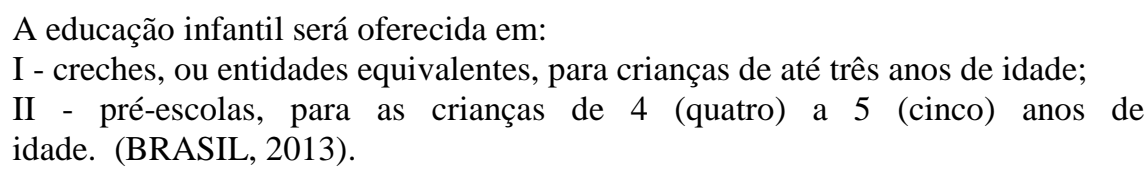

Observa-se que o pré-escolar passa a ser obrigatório, isso significa que os responsáveis, tanto o poder público como as famílias, são obrigados a cumprir o prescrito. O ensino de zero a três anos, por sua vez, embora seja direito da criança, ainda não é obrigatório, afastando tanto do poder público como das famílias a obrigatoriedade de sua realização. Assim, o texto atualizado da LDBEN compreende a educação infantil como parte do sistema de ensino brasileiro, sendo reconhecida como um direito da criança. No entanto, a obrigatoriedade de atendimento da demanda, pelo poder público, ocorrerá a partir dos quatro anos de idade.

Dos documentos que norteiam os encaminhamentos pedagógicos da educação infantil, destacamos as Diretrizes Curriculares Nacionais para a Educação Infantil DCNEI (Resolução no 5, de 17 de dezembro de 2009). As Diretrizes estabelecem que o currículo deve contemplar um conjunto de práticas que busquem articular as experiências e os saberes das crianças com os conhecimentos que fazem parte do patrimônio cultural, artístico, ambiental, científico e tecnológico, de modo a promover o desenvolvimento integral das crianças de zero a cinco anos de idade.

Segundo as DCNEI, a proposta curricular da Educação Infantil deve ter como eixos norteadores as interações e as brincadeiras. Em seu texto, as Diretrizes destacam, ainda, que a criança é um sujeito histórico e de direitos que, nas interações, relações e práticas cotidianas que vivencia, constrói sua identidade pessoal e coletiva, brinca, imagina, fantasia, deseja, aprende, observa, experimenta, narra, questiona e constrói sentidos sobre a natureza e a sociedade, produzindo cultura. Destaca ainda que as propostas pedagógicas de Educação Infantil devem respeitar os princípios éticos, políticos e estéticos. Éticos: da autonomia, da responsabilidade, da solidariedade e do respeito ao bem comum, ao meio ambiente e às diferentes culturas, identidades e singularidades. Políticos: dos direitos de cidadania, do exercício da criticidade e do respeito à ordem democrática. Estéticos: da sensibilidade, da criatividade, da ludicidade e da liberdade de expressão nas diferentes manifestações artísticas e culturais. Em outras palavras, educar e cuidar na instituição de educação infantil significa respeitar e garantir os direitos de todas as crianças ao bem-estar, 
à expressão, ao movimento, à segurança, à brincadeira, ao contato com a natureza e com o conhecimento científico, independentemente de classe, gênero, etnia ou religião.

A perspectiva estabelecida pelas Diretrizes Curriculares Nacionais para a Educação Infantil pode ser identificada nos documentos do Estado do Paraná. Mais particularmente, a Deliberação 003/99 do Conselho Estadual de Educação (CEE), em seu Art. 6º ressalta que:

\begin{abstract}
A educação infantil deve cumprir com suas duas funções: educar e cuidar, sendo estas indispensáveis e indissociáveis, para promover o bem estar da criança, seu desenvolvimento físico, motor, intelectual, emocional, moral e social, estimulando a criança a interessar-se pelo processo do conhecimento do ser humano, da natureza e da sociedade. Isto deve ocorrer, num processo prazeroso, que valorize o lúdico, a cultura, as múltiplas formas de comunicação, diálogo e interação. (PARANÁ, 1999).
\end{abstract}

O texto da lei reconhece que este nível de ensino agrega a função de cuidar e de educar as crianças, sendo indissociáveis as preocupações com estas duas atribuições para o seu desenvolvimento integral. A Deliberação $n^{\circ}$ 02/2014, do Conselho Estadual de Educação do Paraná, acrescenta uma palavra a mais entre os termos cuidar e educar, que é o brincar. Esta tríade deve caminhar vinculada, não havendo fragmentação.

Assim, é possível perceber que o cuidar, o educar e o brincar são conceitos que estiveram presentes, de forma diferente, no transcorrer da história da educação infantil no Brasil. No contexto atual, espera-se que a instituição de educação infantil atue com esses fins, estabelecendo uma visão integrada do desenvolvimento da criança com base em concepções que respeitem a diversidade e a realidade peculiar da infância.

\title{
CONSIDERAÇÕES FINAIS
}

Pela a análise da legislação, tanto brasileira como paranaense, é possível afirmar que a institucionalização da educação infantil no Brasil ainda se encontra em processo de consolidação, tendo em vista que sua obrigatoriedade, em lei, está prevista apenas a partir dos quatro anos de idade. Além disso, o fato de se estar previsto em lei não significa que a administração dos municípios, responsáveis por sua implantação, estaria realizando de forma efetiva aquilo que lhes é imposto. Historiar os desdobramentos, na prática, das alterações trazidas pela inclusão de parte da educação pré-escolar como obrigatória traria outra dimensão desse processo.

Outra questão é que, a trajetória deste nível de ensino é marcada pela existência de diferentes nomenclaturas que carregam, em si, as finalidades e a faixa etária atendida. Como pudemos observar, há diferentes interpretações, nos estudos realizados, em relação aos fins destas instituições. Neste sentido, é possível interpretar que estas interpretações existentes podem revelar que, ao exercerem suas atividades institucionais para a qual foram criadas, muitas ultrapassaram estes limites, influenciadas pelos debates que 
circulavam na época em torno da importância do estímulo ao desenvolvimento infantil. Só será possível afirmar o que de fato ocorreu nestes diferentes espaços, se nos aventurarmos em pesquisas que revelem a sua prática cotidiana.

Neste sentido, consideramos que a história da educação na infância necessita ser revisitada, trazendo novos objetos e olhares interpretativos. Perguntas como: Quais eram as práticas realizadas pelas creches e escolas maternais? O que ocorria com as crianças no interior destas instituições? Quem eram os profissionais que trabalhavam em seu interior? Como era a sua organização interna?

Da mesma maneira, os orfanatos criados e administrados pelas Irmandades. De que maneira eram cuidadas estas crianças? Quais práticas eram desenvolvidas com as crianças? Como se organizavam estes espaços? Quem eram os sujeitos que se ocupavam das atividades com as crianças?

Responder a estas perguntas significaria adentrar no universo interno destas instituições, procurando analisar a prática cotidiana destes espaços e o que elas produziram como cultura. Identificar os produtos destes espaços é buscar compreender o que é cultura escolar e o que configuraria o seu estatuto institucional de fazer próprio. É de fato procurar preencher esta lacuna na história da educação infantil. É identificar, na sua forma estrutural, na organização de suas atividades, nos comportamentos sociais por ela instituídos e na composição de um espaço próprio, as possibilidades de se construir uma história renovada das instituições de educação infantil.

\section{REFERÊNCIAS}

AQUINO, L. As políticas sociais para a infância a partir de um olhar sobre a história da criança no Brasil. In: ROMAM, E. D.; STEYER, V. E. (Org.). A criança de 0 a 6 anos e a educação infantil: um retrato multifacetado. Canoas, RS: Ulbra, 2001.

ARCE, A. Friedrich Froebel: o pedagogo dos jardins de infância. Petrópolis: Vozes, 2002 .

BASTOS, M. H. C. Jardim de Crianças - o pioneirismo do Dr. Menezes Vieira (18751887). In: MONARCHA, C. (Org.). Educação da infância brasileira 1875 - 1983. Campinas: Autores Associados; São Paulo: FAPESP, 2001.

BRASIL. Constituição (1988). Constituição da República Federativa do Brasil. Brasília, DF: Senado Federal, Centro Gráfico, 1988.

BRASIL. Decreto n ${ }^{\circ} 7.247$, de 19 de abril de 1879. Reforma o ensino primário e secundário no município da Corte e o superior em todo o Império. Disponível em: <http://www2.camara.leg.br/legin/fed/decret/1824-1899/decreto-7247-19-abril-1879547933-publicacaooriginal-62862-pe.html>. Acesso em: 21 nov. 2016 
BRASIL. Lei no 4.024/61, de 20 de dezembro de 1961. Fixa as Diretrizes e Bases da Educação Nacional. Disponível em: <http://www2.camara.leg.br/legin/fed/lei/19601969/lei-4024-20-dezembro-1961-353722-publicacaooriginal-1-pl.html>. Acesso em: 21 nov. 2016.

BRASIL. Lei n ${ }^{\circ}$ 5.692/71, de 11 de agosto de 1971. Estabelece as Diretrizes e Bases da Educação Nacional. Disponível em: <http://www2.camara.leg.br/legin/fed/lei/19701979/lei-5692-11-agosto-1971-357752-publicacaooriginal-1-pl.html>. Acesso em: 21 nov. 2016.

BRASIL. Lei n ${ }^{\circ}$ 9.394/96, de 20 de dezembro de 1996. Estabelece as Diretrizes e Bases da Educação Nacional. Disponível em: <http://www.planalto.gov.br/ccivil03/leis/L9394. htm>. Acesso em: 21 nov. 2016.

BRASIL. Lei $\mathrm{n}^{\circ} 12.796$ de 2013. Altera a Lei $\mathrm{n}^{\circ}$ 9.394, de 20 de dezembro de 1996, que estabelece as diretrizes e bases da educação nacional, para dispor sobre a formação dos profissionais da educação e dar outras providências. Disponível em: <http://www.planalto. gov.br/ccivil_03/_ato2011-2014/2013/lei/112796.htm.>. Acesso em: 21 nov. 2016.

BRASIL. Ministério da Educação. Câmara de Educação Básica do Conselho Nacional de Educação. Parecer CEB 020/2009; Resolução CEB 5/2009. Diretrizes Curriculares Nacionais para a Educação Infantil. Brasília: MEC/SEF, 2009.

BRASIL. Ministério do Bem-Estar Social. Centro Brasileiro para a Infância e Adolescência. Lei n. 8069, de 13 de julho de 1990. Dispõe sobre o Estatuto da Criança e do Adolescente e dá outras providências. Diário Oficial da República Federativa do Brasil. Brasília, DF, 16 jul.1990.

CHARTIER, R. O Mundo como representação. Estudos Avançados, v. 5, n. 11, p. 173191, jan./abr. 1991.

DROUET, R. C. da R. Fundamentos da educação pré-escolar. São Paulo: Ática, 1990.

FROEBEL, F. A educação do homem. Tradução de Maria Helena Câmara Bastos. Passo Fundo: UPF, 2001.

GARNIER, P. A educação infantil e a questão da escola: o caso da França. Tradução de Denise Radanovic Vieira. Cadernos de Pesquisa, v. 44, n. 151, p. 62-82, jan./mar. 2014.

KISHIMOTO, T. M. A pré-escola em São Paulo. São Paulo: Loyola, 1988.

KUHLMANN JÚNIOR M. Educando a infância brasileira. In: LOPES, E. M. T.; FARIA FILHO, L. M.; VEIGA, C. G. (Org.). 500 anos de educação no Brasil. Belo Horizonte: Autêntica, 2000b. p. 469-496. 
KUHLMANN JÚNIOR, M. Histórias da educação infantil brasileira. Revista Brasileira de Educação, Rio de Janeiro, n. 14, p. 5-18, maio/ago. 2000a.

KUHLMANN JÚNIOR, M. Infância e educação infantil: uma abordagem histórica. Porto Alegre: Mediação, 1998.

KUHLMANN JÚNIOR M. Infância e educação infantil: uma abordagem histórica. Porto Alegre: Mediações, 2001.

OLIVEIRA, S. M. L. O. A legislação e as políticas para a educação infantil: avanços, vazios e desvios. In: MACHADO, M. L. A. (Org.). Encontros e desencontros em educação infantil. São Paulo: Cortez, 2002.

PARANÁ. Deliberação n. 020/78 - Indicação n. 001/78, de 10 de agosto de 1978. Fixa normas para Educação Pré-escolar e funcionamento de Jardim de Infância. Secretaria de Estado da Educação e da Cultura. Departamento de Ensino de $1^{\circ}$ grau. Currículo, Curitiba, ano 4, n. 38, p. 14-24, 1978.

PARANÁ. Deliberação do Conselho Nacional de Educação do Paraná, nº 02/2014. Normas e Princípios para a Educação Infantil no Sistema de Ensino do Estado do Paraná. Disponível em: <http://www.cee.pr.gov.br/arquivos/File/pdf/Deliberacoes/2014/Del_02_ 14.pdf>. Acesso em: 21 nov. 2016.

PARANÁ. Deliberação do Conselho Nacional de Educação do Paraná, nº 003/1999. Dispõe sobre normas para Educação Infantil no Sistema Estadual de Ensino do Paraná. Disponível em: <http://www.crianca.mppr.mp.br/modules/conteudo/conteudo.php? conteudo=929>. Acesso em: 21 nov.2016.

PESTALOZZI, J. H. Antologia de Pestalozzi. Tradução de Lorenzo Luzuriaga. Buenos Aires: Losada, 1946.

RIZZO, G. Educação Pré-Escolar. 2. ed. Rio de Janeiro: Francisco Alves, 1983.

ROSSI, E. R. A institucionalização da escola primária formal e obrigatória: estratégias de imposição e utilização - considerações sobre a reforma educacional paulista de 1920. In: CONGRESSO BRASILEIRO DE HISTÓRIA DA EDUCAÇÃO, 3., 2004, Curitiba. Anais... Curitiba, 2004. p. 1-10.

SOUSA, A. M. C. de. Educação infantil: uma proposta de gestão municipal. Campinas: Papirus, 1996.

SOUZA, R. F. Objetos de ensino: a renovação pedagógica e material da escola primária no Brasil, no século XX. Educar em Revista, Curitiba, n. 49, p. 103-120, jul./set. 2013.

ZAMBON. M. de. C. A creche privada religiosa no município de São Carlos - S.P.: origem, percurso e organização. In: SEMINÁRIO NACIONAL DE ESTUDOS 
EPESQUISAS, 7., 2006, Campinas. Anais... Campinas: Revista HISTEDBR On-line, 2006. p. 1-18.

\section{Notas}

${ }^{1}$ Mestre em educação pelo Programa de pós-graduação em da Educação pela Universidade Estadual de Maringá (UEM).

${ }^{2}$ Professora Associada do Programa de pós-graduação em da Educação pela Universidade Estadual de Maringá (UEM).

${ }^{3}$ Professora Associada do Programa de pós-graduação em da Educação pela Universidade Estadual de Maringá (UEM).

${ }^{4}$ Espécie de caixa giratória onde se colocavam as crianças enjeitadas, nos asilos e orfanatos. Para a compreensão desse conceito, consultar a obra História da Criança no Brasil de Mary Del Priore (1991).

${ }^{5}$ Marie Pape-Carpantier (1815-1878): professora das primeiras salas de asilo, na França; diretora do curso prático de formação de professoras (1847-1874); escreveu inúmeros periódicos pedagógicos. Foi ela que criou a caixa de Lições de Coisas que é como uma biblioteca de coisas, um instrumento para as lições sobre origem, a história e fabricação das principais coisas de uso geral na vida cotidiana.

${ }^{6}$ A Lei 11.274, de 6 de fevereiro de 2006, altera a duração do Ensino Fundamental para nove anos, com matrícula obrigatória a partir dos seis anos de idade. Essa medida prevê implantação até 2010 pelos Municípios, Estados e Distrito Federal. Durante esse período, os sistemas de ensino terão prazo para adaptarse ao novo modelo de pré-escolas, que passarão a atender crianças de quatro e cinco anos de idade.

Submetido em: 07/052017

Publicado em: 30/06/2017 